\title{
Protected versus Unprotected Carotid Artery Stenting : Meta-Analysis of the Current Literature
}

\author{
Young Dae Cho, M.D., Sung-Eun Kim, M.D., ${ }^{2}$ Jeong Wook Lim, M.D., ${ }^{3}$ Hyuk Jai Choi, M.D., ${ }^{4}$ Yong Jun Cho, M.D., ${ }^{4}$ \\ Jin Pyeong Jeon, M.D. 4,5 \\ Department of Radiology,' Seoul National University College of Medicine, Seoul, Korea \\ Department of Emergency Medicine, ${ }^{2}$ Seoul Emergency Operations Center, Seoul, Korea \\ Department of Neurosurgery, ${ }^{3}$ Chungnam National University College of Medicine, Daejeon, Korea \\ Department of Neurosurgery, ${ }^{4}$ Hallym University College of Medicine, Chuncheon, Korea \\ Institute of New Frontier Research, ${ }^{5}$ Hallym University College of Medicine, Chuncheon, Korea.
}

Objective : To compare peri-operative any symptomatic stroke after carotid angioplasty and stenting (CAS), based on the application or absence of a cerebral protection device.

Methods: A systematic literature review using PubMed, Embase, and the Cochrane Central was done across an online data base from January 1995 to October 2016. Procedures which were performed due to carotid dissection or aneurysm, procedures using covered stents or conducted in an emergency, were excluded. The primary endpoint was perioperative any symptomatic stroke within 30 days after the procedure. A fixed effect model was used in cases of heterogeneity less than $50 \%$.

Results : In the 25 articles included in this study, the number of stroke events was 326 (2.0\%) in protected CAS and 142 (3.4\%) in unprotected CAS. The use of cerebral protection device significantly decreased stroke after CAS (odds ratio [OR] $0.633,95 \%$ confidence interval $[\mathrm{Cl}] 0.479-0.837, p=0.001)$. In the publication bias analysis, Egger's regression test disclosed that the intercept was -0.317 ( $95 \% \mathrm{Cl}-1.015-0.382, p=0.358$ ). Regarding symptomatic patients (four studies, 539 CAS procedures), the number of stroke was six (1.7\%) in protected CAS and 11 (5.7\%) in unprotected CAS. The protective effect against stroke events by cerebral protection device did not have a statistical significance (OR $0.455,95 \% \mathrm{Cl} 0.151-1.366, p=0.160$ ).

Conclusion : The use of protection device significantly decreased stroke after CAS. However, its efficacy was not demonstrated in symptomatic patients. Routine use of protection device during CAS should be critically assessed before mandatory use.

Key Words : Carotid artery stenosis · Stents · Meta-analysis.

\section{INTRODUCTION}

Distal cerebral protection devices have been widely used during carotid angioplasty and stenting (CAS), to reduce thromboembolic complications. However, there are concerns of possible thromboembolic events during the placement of protection device in patients with tortuous carotid artery, near-occlusion of carotid artery, or thrombus in stenotic $\operatorname{area}^{36)}$. In some patients, stroke after CAS occurs despite the use of protection device. Although previous studies, including

- Received : February 1, 2017 •Revised : April 26, 2017 •Accepted : September 8, 2017

- Address for reprints : Jin Pyeong Jeon, M.D.

Department of Neurosurgery, Hallym University College of Medicine, 1 Hallimdaehak-gil, Chuncheon 24252, Korea

Tel : +82-33-240-5171, Fax : +82-33-240-9970, E-mail : jjs6553@daum.net

This is an Open Access article distributed under the terms of the Creative Commons Attribution Non-Commercial License (http://creativecommons.org/licenses/by-nc/4.0) which permits unrestricted non-commercial use, distribution, and reproduction in any medium, provided the original work is properly cited. 
systematic reviews $^{12,40)}$, showed the efficacy of protected device in reducing perioperative complications after CAS, some studies have doubted the real effectiveness of protection device $^{2,30,36)}$. Two studies recently reported and exhibited disagreement regarding the efficacy of protection device ${ }^{15,19)}$.

Meta-analysis of treatment outcome between CAS and carotid endarterectomy (CEA) has been updated to assess the treatment efficacies ${ }^{45}$. However, a systematic review and meta-analysis of treatment outcome between protected and unprotected CAS has not been reported since 2009, although a number of studies have been continuously published. Here, we conducted a meta-analysis to evaluate perioperative stroke after CAS, based on whether or not a cerebral protection device was used.

\section{MATERIALS AND METHODS}

\section{Search strategy}

Core search between January 1990 and October 2016 through PubMed, Embase, and the Cochrane Central was done, using the key words "carotid stenosis", "stents", "balloon", "carotid angioplasty", "percutaneous transluminal angioplasty", "stroke”, "myocardial infarction”, "death”, "perioperative complications", and "mortality"12,40).

Our criteria for inclusion in this study were : 1) symptomatic and/ or asymptomatic stenosis in the internal carotid artery or carotid bifurcation, 2) CAS procedures with or without cerebral protection through common femoral artery over $20^{12}$, and 3) the number of peri-procedural complications such as stroke, death or myocardial infarction within 30 days was reported separately through a comparative study between protected and unprotected $\mathrm{CAS}^{40}$. Stroke was defined as any sudden neurologic deficits due to cerebral infarction ${ }^{39)}$ including bilateral involvement. Asymptomatic signal change on brain MRI was not included for this meta-analysis. In case of overlap, the most recently published article was selected for analysis. Assessing risk of bias in included studies was performed using Cochrane risk of bias for randomized controlled studies (Supplementary Fig. 1) and Newcastle-Ottawa scale for nonrandomized studies. The exclusion criteria included : 1) incomplete data or unclear distinction between protected and unprotected CAS, 2) review articles or case reports, 3) procedures due to dissection, carotid aneurysm, urgently conducted procedure or the use of covered stents, and 4) other procedural approach, other than common femoral artery ${ }^{12,23,34)}$.

\section{Data extraction}

An extensive electronic search was performed by an experienced researcher. Then articles were reviewed and selected on specific criteria by two investigator (J.P.J. and Y.S.K.) followed by discussion. Disagreements between the two authors were resolved by discussion and consultation with a third author. The primary endpoint was perioperative any symptomatic stroke within 30 days after the procedure ${ }^{40)}$. Subgroup analyses were performed only for symptomatic carotid stenosis. This meta-analysis was performed according to the Preferred Reporting Items for Systematic Reviews and Meta-Analyses (PRISMA) guidelines.

\section{Statistical analysis}

Dichotomous variables are presented as odds ratio (OR) with a $95 \%$ confidence interval (CI). Heterogeneity was evaluated by using the $\mathrm{I}^{2}$ test. If $\mathrm{I}^{2}$ was less than $50 \%$, a fixed effect model was used ${ }^{21)}$. Publication bias was determined using Begg's funnel plot and Egger's test of the intercept ${ }^{3,11,22)}$. Comprehensive meta-analysis (CMA) software (CMA v2.2.064, Biostat, Englewood, NJ, USA) was used for all the above, with statistical significance indicated at $p<0.05$.

\section{RESULTS}

\section{Identification of relevant studies}

Fig. 1 displays a flow diagram of the detailed search process. After screening the records and deciding eligibility, 25 articles were included (Table 1). At the subgroup analysis, four studies included the data of symptomatic carotid stenosis.

\section{Comparison of the perioperative stroke between protected and unprotected CAS}

A total of 20670 CAS procedures from 25 studies were included in this analysis (Fig. 2A). Among them, 16440 procedures were done with cerebral protection device and 4230 were done without protection device. The number of stroke was $326(2.0 \%)$ in protected CAS and 142 (3.4\%) in unprotected CAS. The use of cerebral protection device significantly decreased stroke after CAS (OR 0.633, 95\% CI 0.479-0.837, 


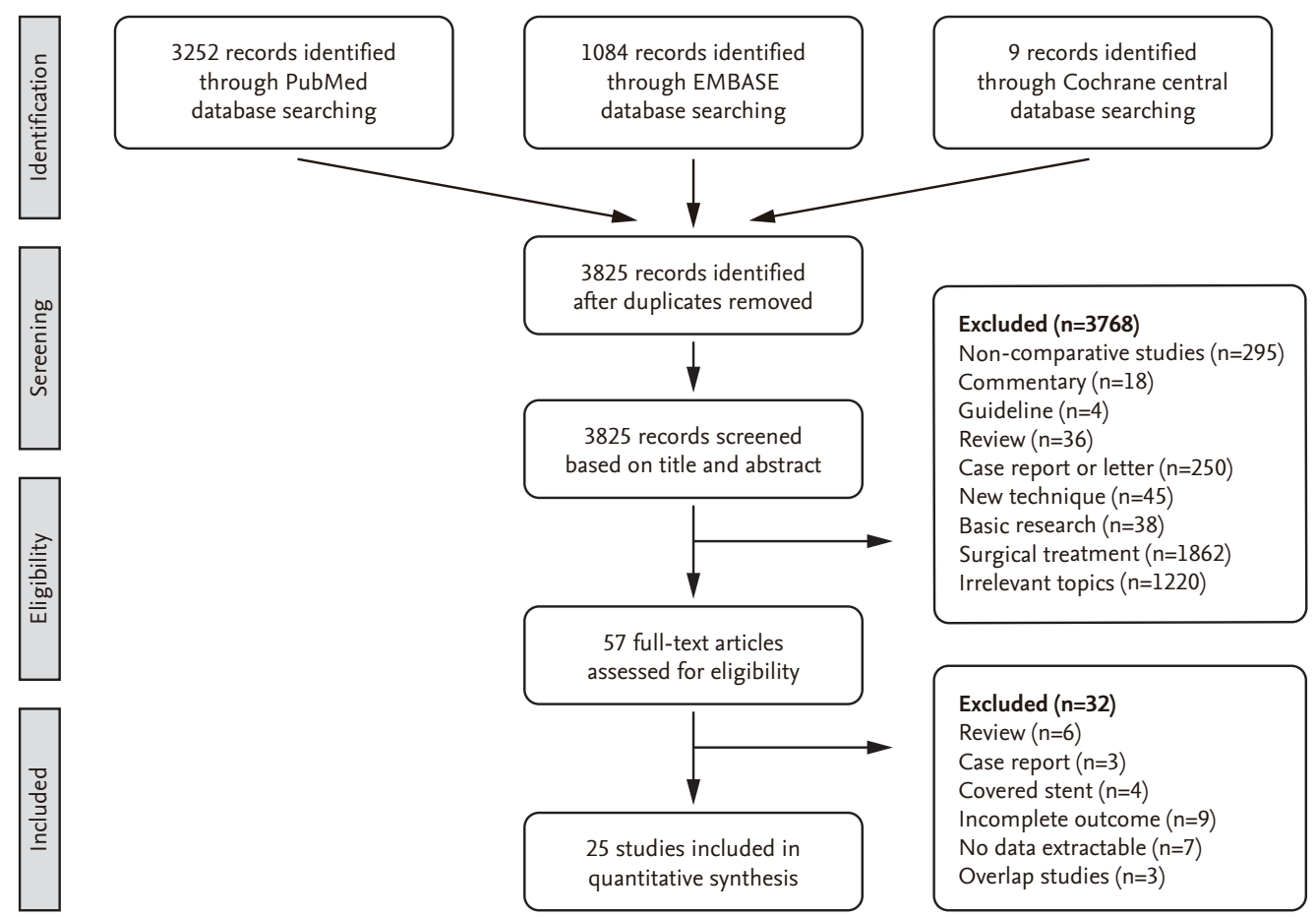

Fig. 1. Flow diagram for identification of relevant studies.

$p=0.001)$. In the publication bias analysis for comparison between protected and unprotected CAS, Egger's regression test disclosed that the intercept was -0.317 (95\% CI -1.015-0.382, $p=0.358$ ). Accordingly, there was no evidence of publication bias in this comparison (Fig. 2B).

\section{Comparison of the perioperative stroke in symp- tomatic carotid stenosis}

A total of 539 CAS procedures from four studies were included in this analysis (Fig. 3A). Of theses, 345 procedures were done with cerebral protection device and 194 were done without protection device. The number of stroke was six (1.7\%) in protected CAS and 11 (5.7\%) in unprotected CAS. The use of cerebral protection device did not decrease the events of stroke after CAS (OR 0.455, 95\% CI 0.151-1.366, $p=0.160$ ). In the publication bias analysis for comparison between protected and unprotected CAS, Egger's regression test disclosed that the intercept was 1.6592 (95\% CI -13.600$16.918, p=0.686$ ). Accordingly, there was no evidence of publication bias in this comparison (Fig. 3B).

\section{DISCUSSION}

Although many reports are available, the efficacy of protection device in preventing thromboembolic complications during CAS remains inconclusive. Our study showed that using cerebral protection device significantly lowered the stroke. However, its efficacy was not demonstrated in symptomatic lesions.

During the delivery of protection device, thromboembolic complications can occur while passing over the severe stenotic lesions or vulnerable plaque. In addition, protection device sometimes cannot be deployed at the destination site due to the stiffness in the tortuous or kinked carotid artery ${ }^{36)}$. Subsequently, the efficacy of protection device should be assessed by an updated knowledge, although protection devices are widely accepted for the procedure.

Garg et al. ${ }^{12}$ compared total stroke events within 30 days after the procedures between protected and unprotected CAS. They concluded that protected CAS showed a relative risk reduction of 0.59 (95\% CI 0.47-0.73) than unprotected CAS, in 24 studies. Through a systemic review, Touzé et al. ${ }^{40)}$ reported a $4.7 \%(95 \%$ CI $4.1-5.2)$ reduction within the 30 -day risk of 
Protected versus Unprotected CAS | Cho YD, et al.

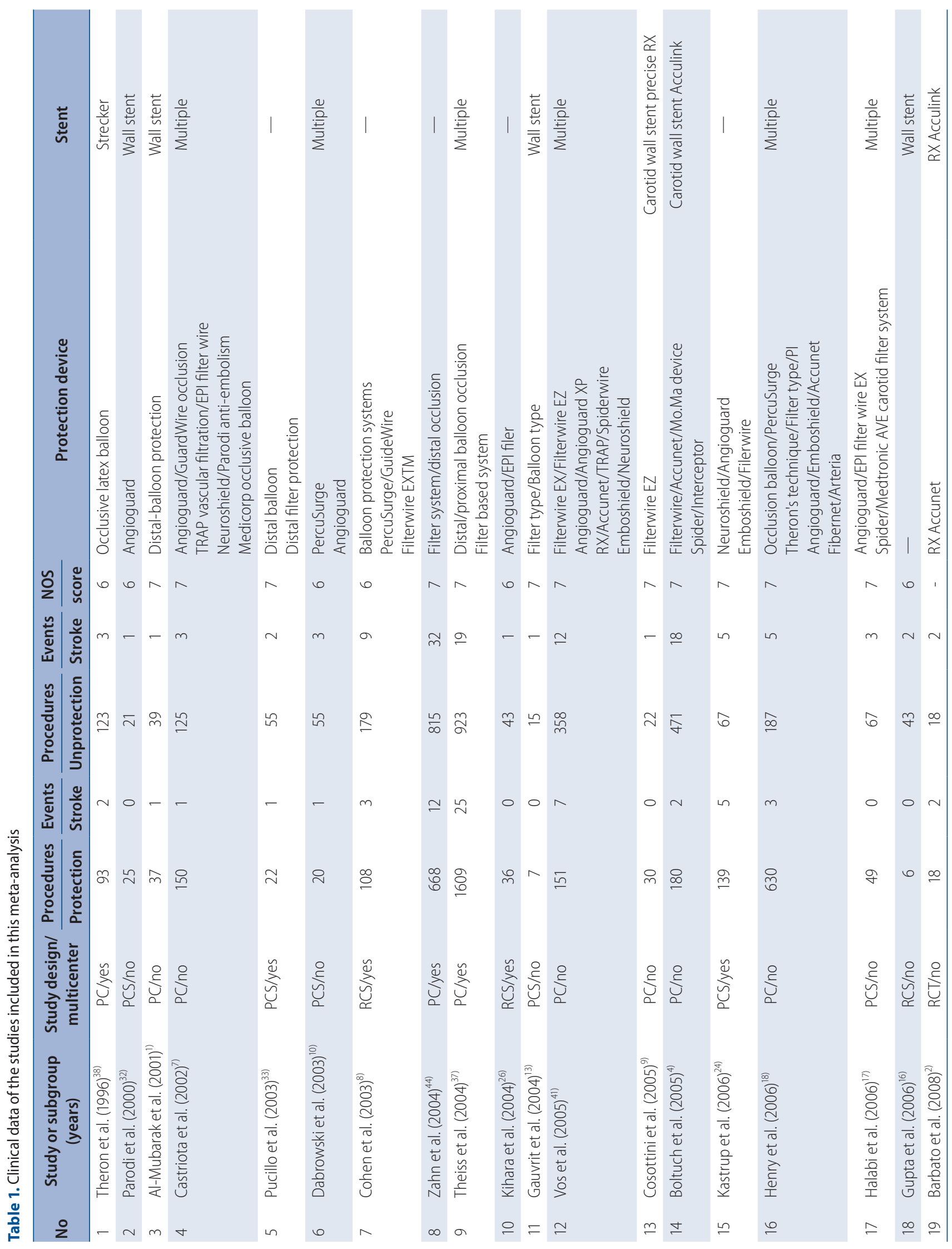




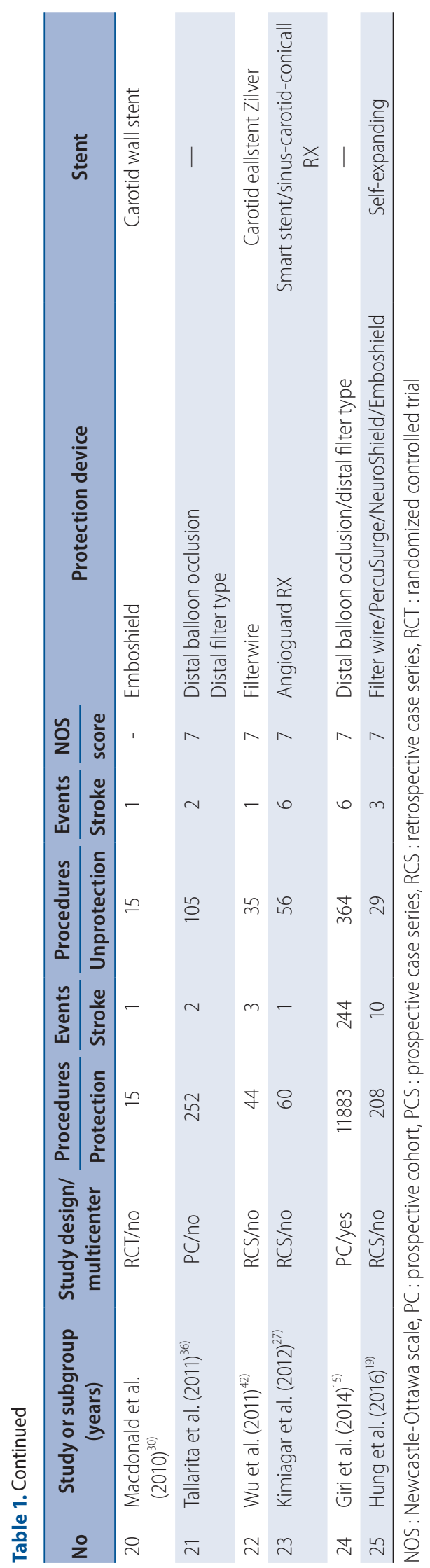

stroke or death rate after CAS. In their study ${ }^{40)}$, the protection device lowered the periprocedural complications with risk reduction of 0.57 (95\% CI 0.43-0.76). Our study also showed that cerebral protection device significantly decreased the events of stroke. However, substantial heterogeneity across the studies can be a concern to interpret the results of previous meta-analysis ${ }^{40)}$. In addition, only two randomized controlled trial (RCT) studies ${ }^{31,35)}$ were enrolled in their investigations. Analyzing three RCT studies, the Cochrane review ${ }^{5}$ reported that the number of either stroke or death within 30 days after CAS did not differ significantly, based on the use of protection device (OR $0.95,95 \%$ CI $0.38-2.41)^{20,31,35)}$. In this metaanalysis, only two studies ${ }^{2,30)}$ provided clear information on stroke and death, respectively, not sum of stroke and death. That was because most previous RCTs have compared treatment outcomes between CAS and CEA, not focusing on the use of protection device. Accordingly, further analysis of individual patient data are necessary.

Symptomatic stenosis affects the periprocedural risk after the procedure. A systemic review ${ }^{40)}$ showed that symptomatic lesion increased the 30-day risk of stroke or death, more than asymptomatic lesions (7.6\%, 95\% CI 6.3-9.1 vs. 3.3\%, 95\% CI 2.6-4.1). Garg et al. ${ }^{12}$ also reported that symptomatic patients had a higher stroke rate than asymptomatic patients, comparing patients who underwent protected (3.8\% vs. $1.7 \%)$ and unprotected CAS (5.6\% and 2.8\%). For symptomatic patients, the protection device exhibited relative stroke risk reduction of 0.67 (95\% CI 0.5-20.86). Kosowski et al. ${ }^{28)}$ compared the long-term adverse events between symptomatic and asymptomatic patients who underwent CAS. The risk of stroke or death did not differ significantly between symptomatic (8.3\%) and asymptomatic patients (8.6\%). In this study, we did not find a significant difference in the number of stroke between protected $(n=6,1.7 \%)$ and unprotected CAS $(n=11,5.7 \%)$ in symptomatic patients (OR $0.455, p=0.160$ ). We think that difference in the primary endpoint (stroke vs. stroke and death) resulted to the disagreement. Accordingly, further large scale RCT studies are required to investigate the periprocedural risk according to the use of protection device, including symptomatic stenosis.

Technical differences in stent type and protection device are related to the periprocedural complications after CAS. The procedures are performed using various stents with different cell designs. Bosiers et al. ${ }^{6}$ reported that the postprocedural 
Study name

$\begin{array}{lcc} & & \\ & \text { Protected } & \text { Unprotected } \\ \text { Theron et al. }(1996)^{38)} & 2 / 93 & 3 / 123 \\ \text { Parodi et al. }(2000)^{32)} & 0 / 25 & 1 / 21 \\ \text { Al-Mubarak et al. }(2001)^{1)} & 1 / 37 & 1 / 39 \\ \text { Castriota et al. }(2002)^{7)} & 1 / 150 & 3 / 125 \\ \text { Pucillo et al. }(2003)^{33)} & 1 / 22 & 2 / 55 \\ \text { Dabrowski et al. }(2003)^{10)} & 1 / 20 & 3 / 55 \\ \text { Cohen et al. }(2003)^{8)} & 3 / 108 & 9 / 179 \\ \text { Zahn et al. }(2004)^{44)} & 12 / 668 & 32 / 815 \\ \text { Theiss et al. }(2004)^{37)} & 25 / 1609 & 19 / 923 \\ \text { Kihara et al. }(2004)^{26)} & 0 / 36 & 1 / 43 \\ \text { Gauvrit et al. }(2004)^{13)} & 0 / 7 & 1 / 15 \\ \text { Vos et al. }(2005)^{41)} & 7 / 151 & 12 / 358 \\ \text { Cosottbini et al. }(2005)^{9)} & 0 / 30 & 1 / 22 \\ \text { Boltuch et al. }(2005)^{4)} & 2 / 180 & 18 / 471 \\ \text { Kastrup et al. }(2006)^{24)} & 5 / 139 & 5 / 67 \\ \text { Henry et al. }(2006)^{18)} & 3 / 630 & 5 / 187 \\ \text { Halabi et al. }(2006)^{17)} & 0 / 49 & 3 / 67 \\ \text { Gupta et al. }(2006)^{16)} & 0 / 6 & 2 / 43 \\ \text { Barbato et al. }(2008)^{2)} & 2 / 18 & 2 / 18 \\ \text { Macdonald et al. }(2010)^{30)} & 1 / 15 & 1 / 15 \\ \text { Tallarita et al. }(2011)^{36)} & 2 / 252 & 2 / 105 \\ \text { Wu et al. }(2011)^{42)} & 3 / 44 & 1 / 35 \\ \text { Kimiagar et al. }(2012)^{27)} & 1 / 60 & 6 / 56 \\ \text { Giri et al. }(2014)^{15)} & 244 / 11883 & 6 / 364 \\ \text { Hung et al. }(2016)^{19)} & 10 / 208 & 3 / 29 \\ & & \end{array}$

Statistics for each study

Odds Lower Upper

$\begin{array}{lll}0.879 & 0.144 & 5.371\end{array}$

$0.268-0.010-6.932$

$\begin{array}{lll}1.056 & 0.064 & 17.516\end{array}$

$0.273 \quad 0.028 \quad 2.657$

$\begin{array}{lll}1.262 & 0.109 & 14.668\end{array}$

$\begin{array}{lll}0.912 & 0.089 & 9.314\end{array}$

$0.540-0.143-2.039$

$\begin{array}{lll}0.448 & 0.229 & 0.876\end{array}$

$\begin{array}{lll}0.751 & 0.411 & 1.371\end{array}$

$\begin{array}{lll}0.388 & 0.015 & 9.822\end{array}$

$\begin{array}{lll}0.644 & 0.023 & 17.822\end{array}$

$\begin{array}{lll}1.402 & 0.541 & 3.632\end{array}$

$\begin{array}{lll}0.235 & 0.009 & 6.047\end{array}$

$\begin{array}{lll}0.283 & 0.065 & 1.231\end{array}$

$\begin{array}{lll}0.463 & 0.129 & 1.657\end{array}$

$\begin{array}{lll}0.174 & 0.041 & 0.736\end{array}$

$\begin{array}{lll}0.186 & 0.009 & 3.688\end{array}$

$\begin{array}{lll}1.277 & 0.055 & 29.707\end{array}$

$\begin{array}{lll}1.000 & 0.125 & 7.995\end{array}$

$\begin{array}{lll}1.000 & 0.057 & 17.621\end{array}$

$\begin{array}{llr}0.412 & 0.057 & 2.964\end{array}$

$2.488 \quad 0.247 \quad 25.023$

$\begin{array}{lll}0.141 & 0.016 & 1.213\end{array}$

$1.251 \quad 0.553 \quad 2.831$

$0.438 \quad 0.113 \quad 1.694$

$\begin{array}{lll}0.633 & 0.479 & 0.837\end{array}$

A Heterogeneity: $x^{2}=17.901 ; d f=24(p=0.808) ; I^{2}=0.00 \%$ Test for overall effect : $Z=-3.208(p=0.001)$

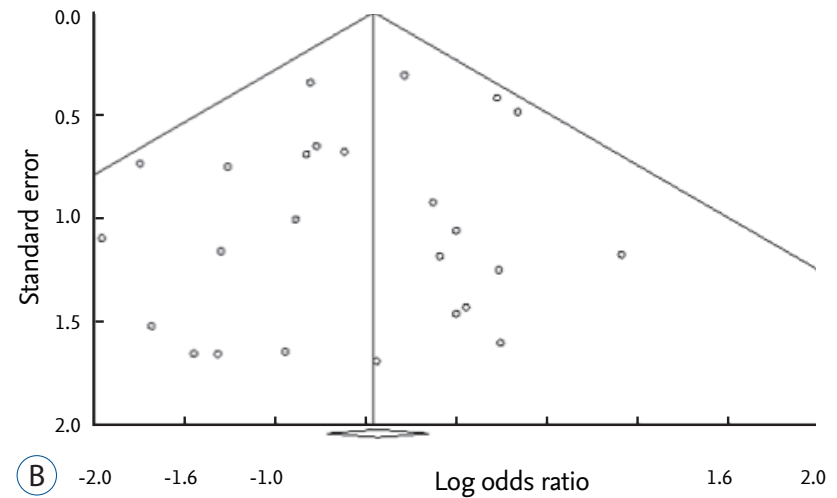

event rate was more pronounced in open cells $(3.4 \%)$ than closed cells $(1.3 \%)$, in particular in symptomatic patients. However, a recent meta-analysis by Kouvelos et al. ${ }^{29)}$ did not show the risk reduction of death (OR $0.69, p=0.21)$ and stroke (OR 1.17, $p=0.37$ ) according to cell design, within 30 days after the procedure. Cerebral protection can be conducted by balloon occlusion of the internal carotid artery above the stenotic lesion, filter instrument and flow-reversal system ${ }^{18)}$. Embolic events are more found in filters than proximal occlusion or flow reversal system while crossing the lesion ${ }^{18)}$. Thus theoretically, proximal embolic protection device can be advanta-

$\begin{array}{rr}\text { Z-value } & p \text {-value } \\ -0.140 & 0.889 \\ -0.793 & 0.428 \\ -0.038 & 0.970 \\ -1.118 & 0.263 \\ 0.186 & 0.853 \\ -0.077 & 0.938 \\ -0.910 & 0.363 \\ -2.346 & 0.019 \\ -0.932 & 0.351 \\ -0.574 & 0.566 \\ -0.259 & 0.795 \\ 0.695 & 0.487 \\ -0.874 & 0.382 \\ -1.683 & 0.092 \\ -1.184 & 0.236 \\ -2.377 & 0.017 \\ -1.103 & 0.270 \\ 0.152 & 0.879 \\ 0.000 & 1.000 \\ 0.000 & 1.000 \\ -0.881 & 0.378 \\ 0.774 & 0.439 \\ -1.784 & 0.074 \\ 0.537 & 0.591 \\ -1.196 & 0.232 \\ -3.208 & 0.001\end{array}$

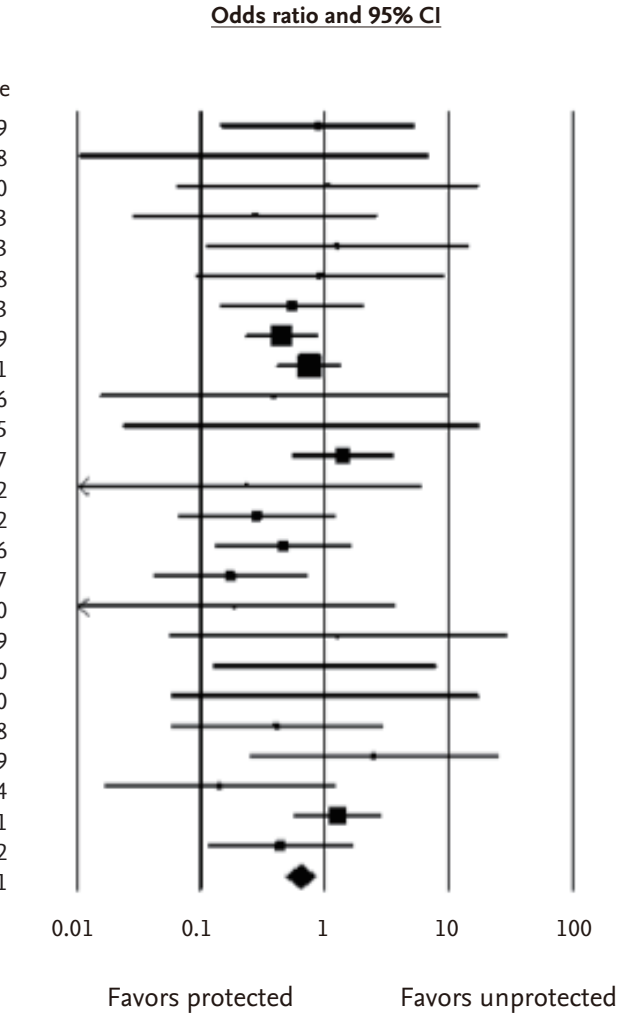

Favors protected

Odds ratio and $95 \% \mathrm{Cl}$

Fig. 2. A : Perioperative stroke events between protected and unprotected carotid angioplasty and stenting. B : Funnel plots for publication bias in perioperative stroke in all studies. $\mathrm{Cl}$ : confidence interval.

geous in preventing stroke during $\mathrm{CAS}^{14)}$. Giri et al. ${ }^{14)}$ compared the clinical outcome between distal and proximal protection devices during CAS. In their study, the 30-day adverse events did not reach significance according to the device types $(p=0.07)$. Zhan et al. ${ }^{43)}$ also reported that in-hospital stroke or death did not differ significantly between filter (10 out of 551, 1.8\%) and distal occlusive (4 out of 176, 2.3\%) embolic protection device (OR 1.04, 95\% CI 0.24-4.44, $p=0.958$ ). Nevertheless, future prospective trials comparing stent design and protection device properties are needed.

There are some limitations in this study. First, most studies 
Study name
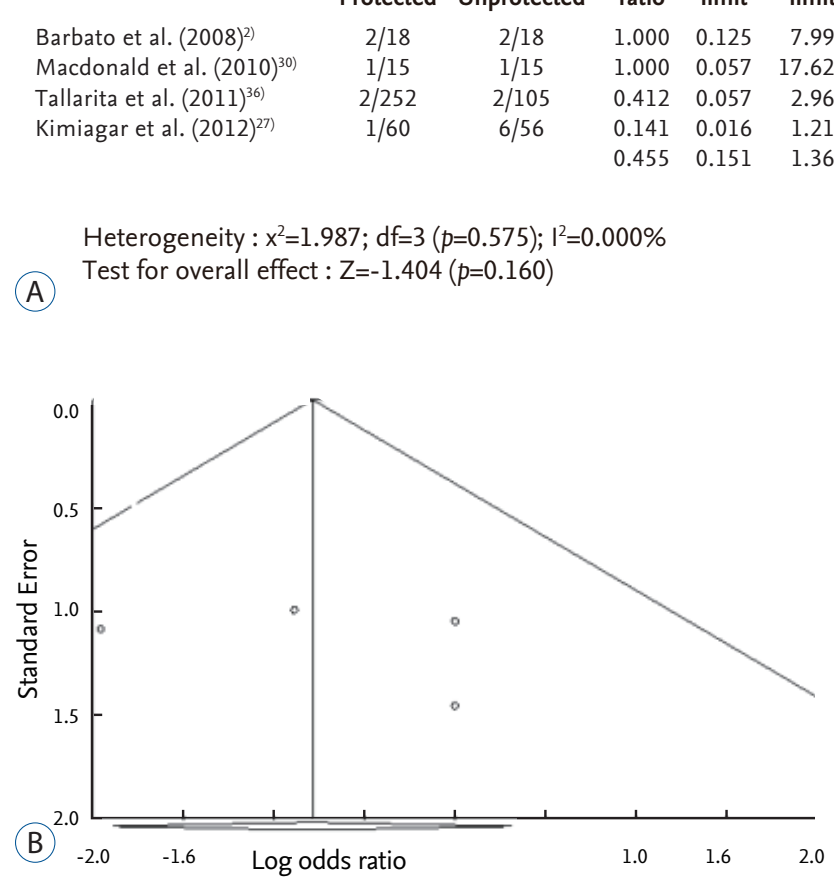

of this investigation did not analyze the efficacy of the protection device according to the symptomaticity. Second, two out of the 25 studies (8\%) are RCTs, although a number of studies have drawn their conclusion from a prospective registry. Third, heterogeneity in terms of primary endpoints (stroke ${ }^{12}$ vs. stroke or death vs. stroke and death) can be a limitation to reach the conclusion in the previous studies. In addition, some studies did not provide clear information on stroke, death, and their summation, respectively. Accordingly, total events can be overestimated because major stroke can be fatal, although total events were estimated as the sum of any stroke or death in previous study ${ }^{25)}$. Accordingly, randomized controlled studies including more detailed data on perioperative complications according to the symptomaticity and risk stratification, and adverse events in long-term observation are required.

\section{CONCLUSION}

Our meta-analysis showed the use of cerebral protection device significantly decreased any symptomatic stroke after the CAS. However, its efficacy was not demonstrated in symp-
Fig. 3. A : Perioperative stroke between protected and unprotected carotid angioplasty and stenting in patients with symptomatic carotid stenosis. B : Funnel plots for publication bias in perioperative stroke in patients with symptomatic carotid stenosis. $\mathrm{Cl}$ : confidence interval.

tomatic patients. Therefore, routine use of protection device during CAS should be critically assessed before mandatory use.

\section{CONFLICTS OF INTEREST}

No potential conflict of interest relevant to this article was reported.

\section{INFORMED CONSENT}

This type of study does not require informed consent.

\section{- Acknowledgements}

This research was supported by a grant (PJ01121401) from BioGreen 21 of the Rural Development Administration, and partly by National Research Foundation of Korea grant funded by the Ministry of Science, Information and Communication Technologies and Future Planning of the Korea Government (No. 2017M3A9E8 033223). 


\section{- Supplementary materials}

The online-only data supplement is available with this article at https://doi.org/10.3340/jkns.2017.0202.001.

\section{References}

1. Al-Mubarak N, Roubin GS, Vitek JJ, lyer SS, New G, Leon MB : Effect of the distal-balloon protection system on microembolization during carotid stenting. Circulation 104 : 1999-2002, 2001

2. Barbato JE, Dillavou E, Horowitz MB, Jovin $T G$, Kanal E, David S, et al. : A randomized trial of carotid artery stenting with and without cerebral protection. J Vasc Surg $47:$ 760-765, 2008

3. Begg $C B$, Mazumdar $M$ : Operating characteristics of a rank correlation test for publication bias. Biometrics 50 : 1088-1101, 1994

4. Boltuch J, Sabeti S, Amighi J, Dick P, Mlekusch W, Schlager O, et al. : Procedure-related complications and early neurological adverse events of unprotected and protected carotid stenting: temporal trends in a consecutive patient series. J Endovasc Ther 12 : 538-547, 2005

5. Bonati LH, Lyrer P, Ederle J, Featherstone R, Brown MM : Percutaneous transluminal balloon angioplasty and stenting for carotid artery stenosis. Cochrane Database Syst Rev (9) : CD000515, 2012

6. Bosiers M, de Donato G, Deloose K, Verbist J, Peeters P, Castriota F, et al. : Does free cell area influence the outcome in carotid artery stenting? Eur J Vasc Endovasc Surg 33 : 135-141; discussion 142-133, 2007

7. Castriota F, Cremonesi A, Manetti R, Liso A, Oshola K, Ricci E, et al. : Impact of cerebral protection devices on early outcome of carotid stenting. J Endovasc Ther 9 : 786-792, 2002

8. Cohen JE, Lylyk P, Ferrario A, Gomori JM, Umansky F : Carotid stent angioplasty: the role of cerebral protection devices. Neurol Res 25 : 162168, 2003

9. Cosottini M, Michelassi MC, Puglioli M, Lazzarotti G, Orlandi G, Marconi $F$, et al. : Silent cerebral ischemia detected with diffusion-weighted imaging in patients treated with protected and unprotected carotid artery stenting. Stroke 36 : 2389-2393, 2005

10. Dabrowski M, Bielecki D, Gołebiewski P, Kwieciński H : Percutaneous internal carotid artery angioplasty with stenting: early and long-term results. Kardiol Pol 58 : 469-480, 2003

11. Egger M, Davey Smith G, Schneider M, Minder C : Bias in meta-analysis detected by a simple, graphical test. BMJ 315 : 629-634, 1997

12. Garg N, Karagiorgos N, Pisimisis GT, Sohal DP, Longo GM, Johanning $J M$, et al. : Cerebral protection devices reduce periprocedural strokes during carotid angioplasty and stenting: a systematic review of the current literature. J Endovasc Ther 16 : 412-427, 2009

13. Gauvrit JY, Delmaire C, Henon H, Debette S, al Koussa M, Leys D, et al. : Diffusion/perfusion-weighted magnetic resonance imaging after carotid angioplasty and stenting. J Neurol 251 : 1060-1067, 2004

14. Giri J, Parikh SA, Kennedy KF, Weinberg I, Donaldson C, Hawkins BM, et al. : Proximal versus distal embolic protection for carotid artery stenting: a national cardiovascular data registry analysis. JACC Cardiovasc
Interv $8:$ 609-615, 2015

15. Giri J, Yeh RW, Kennedy KF, Hawkins BM, Weinberg I, Weinberg MD, et al. : Unprotected carotid artery stenting in modern practice. Catheter Cardiovasc Interv 83 : 595-602, 2014

16. Gupta AK, Purkayastha S, Kapilamoorthy TR, Nair MD, Krishnamoorthy T, Rupa $S$, et al. : Carotid artery stenting: results and long-term follow-up. Neurol India $54:$ 68-72, 2006

17. Halabi M, Gruberg L, Pitchersky S, Kouperberg E, Nikolsky E, Hoffman A, et al. : Carotid artery stenting in surgical high-risk patients. Catheter Cardiovasc Interv 67 : 513-518, 2006

18. Henry M, Polydorou A, Henry I, Anagnostopoulou IS, Polydorou IA, Hugel $\mathrm{M}$ : Carotid angioplasty and stenting under protection. Techniques, results and limitations. J Cardiovasc Surg (Torino) 47 : 519-546, 2006

19. Hung CS, Lin MS, Chen YH, Huang CC, Li HY, Kao HL : Prognostic factors for neurologic outcome in patients with carotid artery stenting. Acta Cardiol Sin 32 : 205-214, 2016

20. International Carotid Stenting Study investigators; Ederle J, Dobson J, Featherstone RL, Bonati LH, van der Worp HB, et al. : Carotid artery stenting compared with endarterectomy in patients with symptomatic carotid stenosis (international carotid stenting study): an interim analysis of a randomised controlled trial. Lancet 375 : 985-997, 2010

21. Jeon JP, Kim JE : A recent update of clinical and research topics concerning adult moyamoya disease. J Korean Neurosurg Soc 59 : 537-543, 2016

22. Jeon JP, Kim JE, Cho WS, Bang JS, Son YJ, Oh CW : Meta-analysis of the surgical outcomes of symptomatic moyamoya disease in adults. J Neurosurg $128: 793-799,2018$

23. Jeon $J S$, Sheen $\mathbf{S H}$, Hwang $G$ : Hemodynamic instability during carotid angioplasty and stenting-relationship of calcified plaque and its characteristics. Yonsei Med J 54 : 295-300, 2013

24. Kastrup A, Nägele T, Groschel K, Schmidt F, Vogler E, Schulz J, et al. : Incidence of new brain lesions after carotid stenting with and without cerebral protection. Stroke 37 : 2312-2316, 2006

25. Kastrup A, Skalej M, Krapf H, Nägele T, Dichgans J, Schulz JB : Early outcome of carotid angioplasty and stenting versus carotid endarterectomy in a single academic center. Cerebrovasc Dis 15 : 84-89, 2003

26. Kihara EN, Andrioli MS, Zukerman E, Peres MF, Porto Júnior PP, Monzillo $\mathrm{PH}$, et al. : Endovascular treatment of carotid artery stenosis: retrospective study of 79 patients treated with stenting and angioplasty with and without cerebral protection devices. Arq Neuropsiquiatr 62 : 10121015, 2004

27. Kimiagar I, Gur AY, Auriel E, Peer A, Sacagiu T, Bass A : Long-term follow-up of patients after carotid stenting with or without distal protective device in a single tertiary medical center. Vasc Endovascular Surg 46 : 536-541, 2012

28. Kosowski M, Zimoch W, Gwizdek T, Konieczny R, Kübler P, Telichowski $A$, et al. : Safety and efficacy assessment of carotid artery stenting in a high-risk population in a single-centre registry. Postepy Kardiol Interwencyjnej 10 : 258-263, 2014

29. Kouvelos GN, Patelis N, Antoniou GA, Lazaris A, Matsagkas MI : Meta- 
analysis of the effect of stent design on 30-day outcome after carotid artery stenting. J Endovasc Ther 22 : 789-797, 2015

30. Macdonald S, Evans DH, Griffiths PD, McKevitt FM, Venables GS, Cleveland TJ, et al. : Filter-protected versus unprotected carotid artery stenting: a randomised trial. Cerebrovasc Dis 29 : 282-289, 2010

31. Mas JL, Chatellier G, Beyssen B, Branchereau A, Moulin T, Becquemin $J$, et al. : Endarterectomy versus stenting in patients with symptomatic severe carotid stenosis. N Engl J Med 355 : 1660-1671, 2006

32. Parodi JC, La Mura R, Ferreira LM, Mendez MV, Cersósimo H, Schönholz C, et al. : Initial evaluation of carotid angioplasty and stenting with three different cerebral protection devices. J Vasc Surg 32 : 1127-1136, 2000

33. Pucillo AL, Mateo RB, Aronow WS : Effect of carotid angioplasty-stenting on short-term mortality and stroke. Heart Dis 5 : 378-379, 2003

34. Rhim JK, Jeon JP, Park JJ, Choi HJ, Cho YD, Sheen SH, et al. : Prediction of prolonged hemodynamic instability during carotid angioplasty and stenting. Neurointervention 11 : 120-126, 2016

35. SPACE Collaborative Group, Ringleb PA, Allenberg J, Brückmann H, Eckstein $H H$, Fraedrich $G$, et al. : 30 day results from the SPACE trial of stent-protected angioplasty versus carotid endarterectomy in symptomatic patients: a randomised non-inferiority trial. Lancet 368 : 1239 1247, 2006

36. Tallarita T, Rabinstein AA, Cloft H, Kallmes D, Oderich GS, Brown RD, et al. : Are distal protection devices 'protective' during carotid angioplasty and stenting? Stroke 42 : 1962-1966, 2011

37. Theiss W, Hermanek P, Mathias K, Ahmadi R, Heuser L, Hoffmann FJ, et al. : Pro-CAS: a prospective registry of carotid angioplasty and stenting. Stroke 35 : 2134-2139, 2004

38. Theron JG, Payelle GG, Coskun O, Huet HF, Guimaraens L : Carotid artery stenosis: treatment with protected balloon angioplasty and stent placement. Radiology 201 : 627-636, 1996

39. Topakian R, Strasak AM, Sonnberger M, Haring HP, Nussbaumer $K$, Trenkler J, et al. : Timing of stenting of symptomatic carotid stenosis is predictive of 30-day outcome. Eur J Neurol 14 : 672-678, 2007

40. Touzé E, Trinquart L, Chatellier G, Mas JL : Systematic review of the perioperative risks of stroke or death after carotid angioplasty and stenting. Stroke 40 : e683-e693, 2009

41. Vos JA, van den Berg JC, Ernst SM, Suttorp MJ, Overtoom TT, Mauser HW, et al. : Carotid angioplasty and stent placement: comparison of transcranial Doppler US data and clinical outcome with and without filtering cerebral protection devices in 509 patients. Radiology 234 : 493-499, 2005

42. Wu YM, Wong HF, Chen YL, Wong MC, Toh CH : Carotid stenting of asymptomatic and symptomatic carotid artery stenoses with and without the use of a distal embolic protection device. Acta Cardiol 66 : 453458, 2011

43. Zahn R, Ischinger T, Mark B, Gass S, Zeymer U, Schmalz W, et al. : Embolic protection devices for carotid artery stenting: is there a difference between filter and distal occlusive devices? J Am Coll Cardiol 45 : 1769-1774, 2005

44. Zahn R, Mark B, Niedermaier N, Zeymer U, Limbourg P, Ischinger T, et al. : Embolic protection devices for carotid artery stenting: better results than stenting without protection? Eur Heart J 25 : 1550-1558, 2004

45. Zhang L, Zhao Z, Ouyang Y, Bao J, Lu Q, Feng R, et al. : Systematic review and meta-analysis of carotid artery stenting versus endarterectomy for carotid stenosis: a chronological and worldwide study. Medicine (Baltimore) 94 : e1060, 2015 
Protected versus Unprotected CAS | Cho YD, et al.

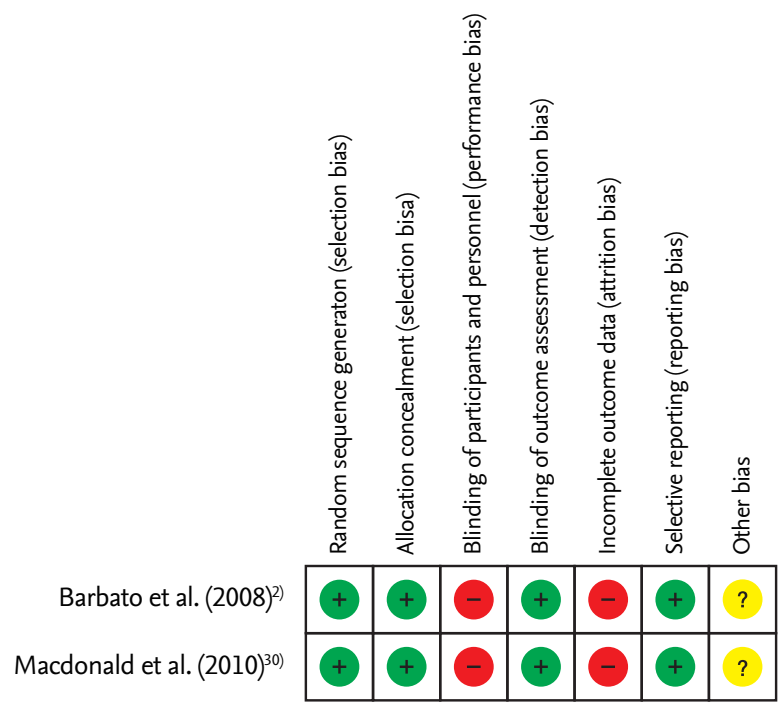

Supplementary Fig. 1. Risk of bias summary for five randomized controlled trial studies. 